\title{
Cognitive decline is associated with an accelerated rate of bone loss and increased fracture risk in women: a prospective study from the Canadian Multicentre Osteoporosis Study
}

Citation for published version (APA):

Bliuc, D., Tran, T., Adachi, J. D., Atkins, G. J., Berger, C., van den Bergh, J., Cappai, R., Eisman, J. A., van Geel, T., Geusens, P., Goltzman, D., Hanley, D. A., Josse, R., Kaiser, S., Kovacs, C. S., Langsetmo, L., Prior, J. C., Nguyen, T. V., Solomon, L. B., ... Canadian Multicentre Osteoporosis Study (CaMos) Research Group (2021). Cognitive decline is associated with an accelerated rate of bone loss and increased fracture risk in women: a prospective study from the Canadian Multicentre Osteoporosis Study. Journal of Bone and Mineral Research, 36(11), 2106-2115. https://doi.org/10.1002/jbmr.4402

Document status and date:

Published: 01/11/2021

DOI:

10.1002/jbmr.4402

Document Version:

Publisher's PDF, also known as Version of record

Document license:

Taverne

Please check the document version of this publication:

- A submitted manuscript is the version of the article upon submission and before peer-review. There can be important differences between the submitted version and the official published version of record. People interested in the research are advised to contact the author for the final version of the publication, or visit the DOI to the publisher's website.

- The final author version and the galley proof are versions of the publication after peer review.

- The final published version features the final layout of the paper including the volume, issue and page numbers.

Link to publication

\footnotetext{
General rights rights.

- You may freely distribute the URL identifying the publication in the public portal. please follow below link for the End User Agreement:

www.umlib.nl/taverne-license

Take down policy

If you believe that this document breaches copyright please contact us at:

repository@maastrichtuniversity.nl

providing details and we will investigate your claim.
}

Copyright and moral rights for the publications made accessible in the public portal are retained by the authors and/or other copyright owners and it is a condition of accessing publications that users recognise and abide by the legal requirements associated with these

- Users may download and print one copy of any publication from the public portal for the purpose of private study or research.

- You may not further distribute the material or use it for any profit-making activity or commercial gain

If the publication is distributed under the terms of Article 25fa of the Dutch Copyright Act, indicated by the "Taverne" license above,

Download date: 26 Apr. 2023 


\title{
Cognitive decline is associated with an accelerated rate of bone loss and increased fracture risk in women: a prospective study from the Canadian Multicentre Osteoporosis Study
}

\author{
Dana Bliuc, ${ }^{1,2}$ (D) Thach Tran, ${ }^{1,2}$ (D) Jonathan D. Adachi, ${ }^{3}$ Gerald J. Atkins, ${ }^{4}$ Claudie Berger, ${ }^{5}$ \\ Joop van den Bergh, ${ }^{6,7}$ Roberto Cappai, John A. Eisman, ${ }^{1,2,9}$ (1) Tineke van Geel, ${ }^{10}$ (1) Piet Geusens, ${ }^{11}$ (1) \\ David Goltzman, ${ }^{12}$ (1) David A. Hanley, ${ }^{13}$ Robert Josse, ${ }^{14}$ Stephanie Kaiser, ${ }^{15}$ Christopher S. Kovacs, ${ }^{16}$ (1) \\ Lisa Langsetmo, ${ }^{17}$ (D) Jerilynn C. Prior, ${ }^{18}$ (D) Tuan V. Nguyen, ${ }^{1,2}$ (i) Lucian B. Solomon, ${ }^{4,19}$ \\ Catherine Stapledon, ${ }^{4}$ and Jacqueline R. Center, ${ }^{1,2}$ \\ For the Canadian Multicentre Osteoporosis Study (CaMos) Research Group \\ ${ }^{1}$ Osteoporosis and Bone Biology, Garvan Institute of Medical Research, Sydney, Australia \\ ${ }^{2}$ Clinical School, St Vincent's Hospital, Faculty of Medicine, University of New South Wales (UNSW) Sydney, Sydney, Australia \\ ${ }^{3}$ Department of Medicine, McMaster University, Hamilton, ON, Canada \\ ${ }^{4}$ Centre for Orthopaedic and Trauma Research, University of Adelaide, Adelaide, Australia \\ ${ }^{5}$ Canadian Multicentre Osteoporosis Study (CaMos) National Coordinating Centre, McGill University, Montreal, QC, Canada \\ ${ }^{6}$ Research School Nutrim, Department of Internal Medicine, Subdivision of Rheumatology, Maastricht University Medical Center, \\ Maastricht, The Netherlands \\ ${ }^{7}$ Department of Internal Medicine, VieCuri Medical Centre of Noord-Limburg, Venlo, The Netherlands \\ ${ }^{8}$ School of Biomedical Sciences, University of Melbourne, Melbourne, Australia \\ ${ }^{9}$ School of Medicine Sydney, University of Notre Dame Australia, Sydney, Australia \\ ${ }^{10}$ Department of Data and Analytics, Máxima Medical Center, Veldhoven, The Netherlands \\ ${ }^{11}$ Biomedical Research Institute, University Hasselt, Hasselt, Belgium \\ ${ }^{12}$ Department of Medicine, McGill University, Montreal, QC, Canada \\ ${ }^{13}$ Department of Medicine, University of Calgary, Calgary, AB, Canada \\ ${ }^{14}$ Department of Medicine, University of Toronto, Toronto, ON, Canada \\ ${ }^{15}$ Department of Medicine, Dalhousie University, Halifax, NS, Canada \\ ${ }^{16}$ Faculty of Medicine, Memorial University, St. John's, NL, Canada \\ ${ }^{17}$ School of Public Health, University of Minnesota, Minneapolis, Minnesota, USA \\ ${ }^{18}$ Department of Medicine and Endocrinology, University of British Columbia, Vancouver, BC, Canada \\ ${ }^{19}$ Orthopaedic and Trauma Service, Royal Adelaide Hospital, Adelaide, Australia
}

\begin{abstract}
Cognitive decline and osteoporosis often coexist and some evidence suggests a causal link. However, there are no data on the longitudinal relationship between cognitive decline, bone loss and fracture risk, independent of aging. This study aimed to determine the association between: (i) cognitive decline and bone loss; and (ii) clinically significant cognitive decline ( $\geq 3$ points) on Mini Mental State Examination (MMSE) over the first 5 years and subsequent fracture risk over the following 10 years. A total of 1741 women and 620 men aged $\geq 65$ years from the population-based Canadian Multicentre Osteoporosis Study were followed from 1997 to 2013. Association between cognitive decline and (i) bone loss was estimated using mixed-effects models; and (ii) fracture risk was estimated using adjusted Cox models. Over $95 \%$ of participants had normal cognition at baseline (MMSE $\geq 24$ ). The annual \% change in MMSE was similar for both genders (women -0.33 , interquartile range [IQR] -0.70 to +0.00 ; and men -0.34 , IQR: -0.99 to 0.01). After multivariable adjustment, cognitive decline was associated with bone loss in women (6.5\%; $95 \%$ confidence interval $[\mathrm{Cl}], 3.2 \%$ to $9.9 \%$ for each percent decline in MMSE from baseline) but not men. Approximately $13 \%$ of participants experienced significant cognitive decline by year 5 . In women, fracture risk was increased significantly (multivariable hazard ratio [HR], $1.61 ; 95 \% \mathrm{Cl}$, 1.11 to 2.34). There were too few men to analyze. There was a significant association between cognitive decline and both bone loss
\end{abstract}

Received in original form December 18, 2020; revised form June 10, 2021; accepted June 22, 2021.

Address correspondence to: Dana Bliuc, MD, MMed, PhD, Garvan Institute of Medical Research, 384 Victoria Street, Darlinghurst, NSW 2010, Australia.

Email: d.bliuc@garvan.org.au

Additional Supporting Information may be found in the online version of this article.

Journal of Bone and Mineral Research, Vol. 00, No. 00, Month 2021, pp 1-10.

DOI: $10.1002 / j b m r .4402$

C 2021 American Society for Bone and Mineral Research (ASBMR). 
and fracture risk, independent of aging, in women. Further studies are needed to determine mechanisms that link these common conditions. ( 2021 American Society for Bone and Mineral Research (ASBMR).

KEY WORDS: AGING; BONE MINERAL DENSITY; COGNITIVE PERFORMANCE; LONGITUDINAL STUDY; OSTEOPOROSIS

\section{Introduction}

D ementia and osteoporosis are highly prevalent in the elderly population and often coexist. Currently worldwide, there are 200 million people affected by osteoporosis ${ }^{(1)}$ and over 35 million by dementia, ${ }^{(2)}$ and these numbers are expected to double over the next two decades because of increasing life expectancy. Both conditions are associated with increased disability, physical decline, loss of independence, and increased mortality risk, and there is some limited evidence that the combination of these conditions results in a worse outcome than either condition alone. ${ }^{(3,4)}$ Despite this, less than $5 \%$ of hip fracture patients with dementia receive appropriate treatment for osteoporosis $^{(5)}$ compared with treatment rates of about $30 \%$ for hip fractures in the general community. The reason for this poor clinical management is unknown but is believed to be at least partly due to a lack of understanding of the nature of the association between these two conditions. ${ }^{(4)}$

Individuals with dementia are at high risk of osteoporosis and hip fracture. ${ }^{(6)}$ It has been estimated that approximately $40 \%$ of patients with hip fracture have a prior diagnosis of dementia. The risk of hip fracture in Alzheimer disease was recently reported in a meta-analysis of nine cohorts from the United States, Canada, and the UK to be over twofold (pooled odds ratio, 2.5; $95 \% \mathrm{Cl}, 2.03-3.24)$ compared to those without dementia. Furthermore, this study also demonstrated that hip bone mineral density (BMD) was lower in those affected (pooled standardized mean difference $-1.12 ; 95 \% \mathrm{Cl},-1.34$ to -0.90 ) compared to controls. ${ }^{(7)}$

Notably, a recent study has demonstrated increased risk of dementia following both hip and non-hip fractures. Although the risk of dementia was highest following hip fracture (60\%), vertebral (47\%), lower (35\%), and upper limb (29\%) fractures were also associated with increased risk. ${ }^{(8)}$ These findings are particularly important as non-hip fractures are very common, affecting two in five women and one in three men after the age of 60 years. ${ }^{(9)}$

The nature of the association between osteoporosis and dementia is not entirely clear. Most authors to date believe that the association between these two common conditions is likely driven by common risk factors such as old age, sedentary lifestyle, physical decline, vitamin D insufficiency, sarcopenia, and propensity to falls. ${ }^{(6)}$ However, there is some evidence that suggests that hip fracture per se may lead to complications which directly precipitate dementia development. ${ }^{(10)}$ Furthermore, at least two studies have shown a significant association between low BMD or bone loss and subsequent cognitive decline in postmenopausal women. ${ }^{(11,12)}$ However, studies investigating the longitudinal long-term association between cognitive decline and both bone loss and fracture risk are lacking.

This study had two aims: to investigate (i) the association between cognitive decline and bone loss over 10 years of follow-up; and (ii) the association between significant cognitive decline over the first 5 study-years and subsequent fracture risk over the following 10 years in participants 65 years and over from the Canadian Multicentre Osteoporosis Study (CaMos).

\section{Subjects and Methods}

\section{Study population and setting}

This study is based on CaMos, an ongoing prospective population based study that started in 1995, with the aim of documenting skeletal health of a randomly selected population of women and men aged $\geq 25$ years. All non-institutionalized Canadians who resided within $50 \mathrm{~km}$ of a study center, representing $\sim 42 \%$ of all Canadians, were eligible. Participants were recruited using randomly generated telephone lists from the regions surrounding nine urban centers in Canada including: St John's Halifax, Québec City, Kingston, Toronto, Hamilton, Saskatoon, Calgary, and Vancouver. A detailed description of the study design and population sampling has been published. ${ }^{(13)}$ CaMos was approved by the Ethics Committee of McGill University and at each participating center.

Of the 9423 participants recruited, 2361 aged $\geq 65$ years were included in the current analysis (Figure 1). Because the aim of this study was to assess the longitudinal association between the rates of bone loss and cognitive decline, eligibility criteria included the presence of at least two BMD measurements (dual-energy X-ray absorptiometry [DXA] at the site of femoral neck) and two cognitive tests assessments (Mini Mental State Examination [MMSE]). The group of people included in the study were younger, had higher baseline femoral neck BMD, MMSE, and Short Form 36 Health Survey (SF-36; Rand Corporation, Santa Monica, CA, USA) scores, had lower prevalence of comorbidities, and better lifestyle factors (more regular physical activity and less smoking) than those who had fewer than two BMD or MMSE measurements.

\section{Study design and data collection}

Data collection was conducted at baseline, year 5, and year 10 using an interviewer-administered structured questionnaire, and yearly through mailed out questionnaires. Information collected during all clinical visits included comorbidities, education (university education or not), lifestyle factors (i.e., smoking, regular physical activity), and quality of life using the SF-36 questionnaire (reported as standardized mental and physical scores). Information on medication and supplements was collected at baseline and yearly. Anthropometric measurements, as well as measurements of BMD and cognitive function were performed at all clinical visits.

In order to ascertain the role of physical characteristics and quality of life on cognitive decline at year 5 , the change in parameters (height, weight, femoral neck BMD, and SF-36 components [standardized mental and physical score]) were calculated for each participant as the percent change between baseline and year 5. Participants were then classified as having significant change (worst quartile) or no change (the remainder). 


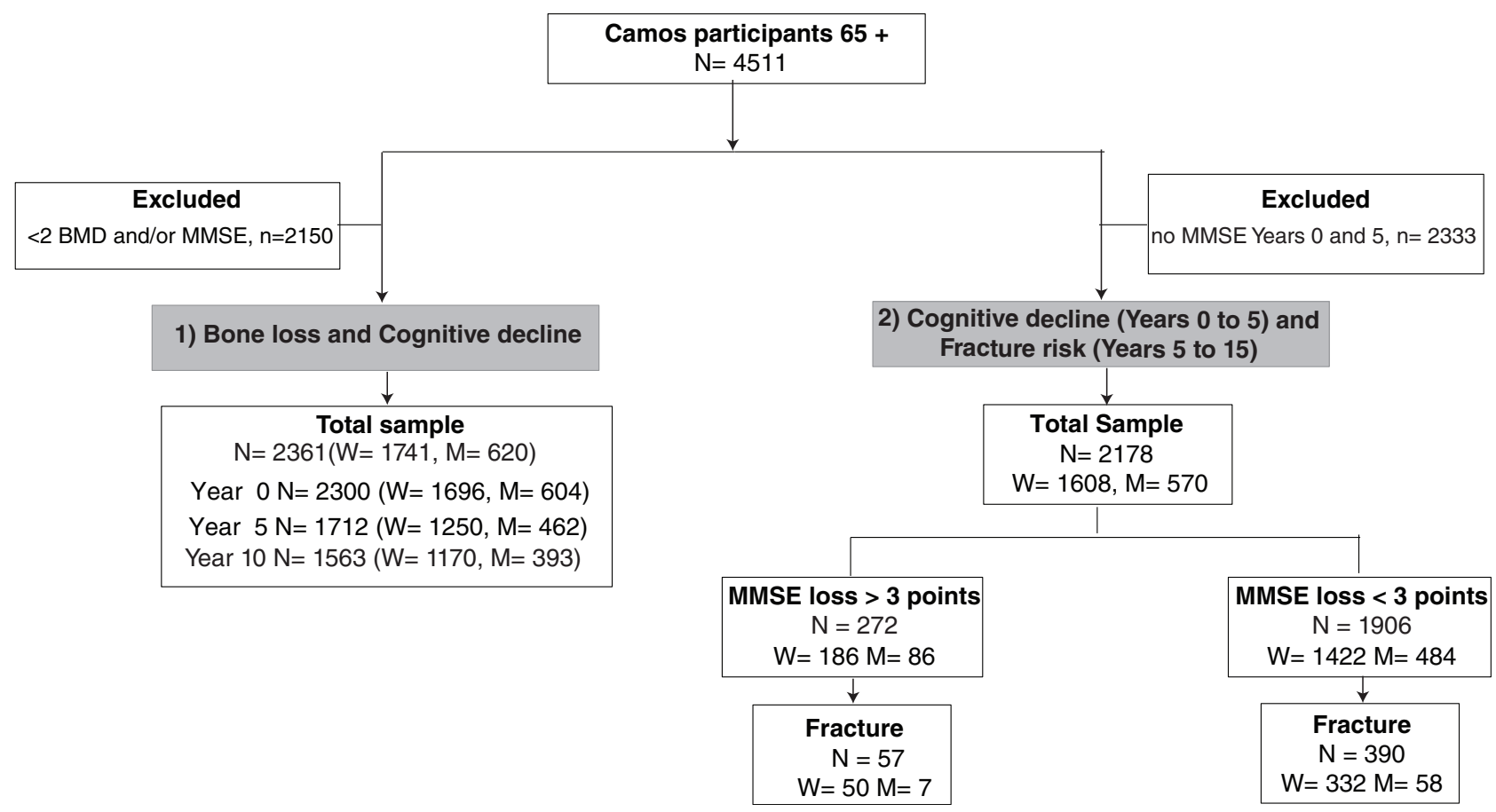

Fig. 1. Flow chart of CaMos participants according to the analytical samples. Abbreviations: BMD, bone mineral density; CaMos, Canadian Multicentre Osteoporosis Study; M, men; MMSE, Mini Mental State Examination; W, women.

\section{Cognitive function assessment}

Cognitive function was assessed using MMSE tests at baseline, year 5, and year 10. MMSE is a set of 30 items that assess shortterm and long-term memory, attention span, concentration, language and communication skills, ability to plan, and ability to understand instruction. The total score ranges from 0 to 30 , with higher scores indicating better global cognition. Several items of MMSE could not be assessed in participants with sensory deficit or arthritis. For participants affected by these conditions, an individualized maximum obtainable score was calculated by subtracting from the total possible score of 30 , the items which could not be assessed. The adjusted score was then calculated as the ratio between person's score on the test and maximum obtainable score multiplied by 30 (https://www.ihpa.gov.au/ sites/default/files/publications/smmse-guidelines-v2.pdf).

Cognitive decline was assessed in two ways. For the first aim, the rate of cognitive decline was calculated as the annualized percent change from baseline. For the second aim, participants were categorized as having significant cognitive decline if they lost more than three points on MMSE between baseline and year 5. Those who lost $<3$ points were considered not affected by cognitive decline. ${ }^{(14,15)}$

\section{Main outcome measurements}

$B M D$

BMD was measured as femoral neck areal BMD (aBMD) at baseline (year 0 ) and then subsequently in year 5 and year 10 . BMD assessment was performed by DXA (Discovery W; Hologic, Bedford, MA, USA). Standardization between DXA scanners was assessed by scanning a single phantom, which was circulated among centers. ${ }^{(16)}$

The primary outcome measurement for this study was the rate of change in BMD calculated as annualized percent change from baseline.

However, because measurements of BMD and cognitive function were performed at the same time points, a reverse analysis with the rate of MMSE decline as the outcome was also performed.

\section{Incident fracture}

Fracture events were identified through the yearly mailed questionnaires and $78 \%$ of fractures were verified by $\mathrm{x}$-ray report. In the verified sample, $>90 \%$ of self-reported fractures were concordant with the $\mathrm{x}$-ray reports.

Information on the fracture site, date of event, and circumstance was obtained by telephone interview. Only minimal trauma fractures, such as those which occur as the result of a fall from standing height or less, were included. Traumatic fractures, as well as pathological (i.e., Paget's disease, metastatic cancer), and fractures of the skull and digits were excluded.

Because the second aim of this study was to assess the effect of significant cognitive decline at year 5 on subsequent fracture risk, incident fracture was defined as the first fragility fracture that occurred from year 5 through year 15 . Incident fractures were classified according to the bone site affected as hip, clinical vertebral, and non-hip non-vertebral fracture (NHNV), which included all the remainder sites (ribs, pelvis, arms, and legs, except fingers and toes). If more than one site was affected in the same event (i.e., multiple fractures), the classification was based on the most proximal ones deemed to be more severe. ${ }^{(9)}$ 
Fragility fracture sustained between baseline and year 5, as well as those prior to recruitment were classified as prior fracture.

\section{Statistical analysis}

Analysis was performed separately for women and men and aimed to answer two specific questions: (i) the longitudinal relationship between the rate of cognitive decline and bone loss; and (ii) the association between significant cognitive decline at year 5 and subsequent fracture risk between year 5 and year 15 .

\section{Longitudinal relationship between rates of cognitive decline and bone loss}

Rates of bone loss and cognitive decline were estimated for each participant as annualized percent change using three measurements (baseline, year 5, and year 10) as well as the total percent change between baseline and year 10, using generalized linear models. Initially, the trajectories of bone loss and cognitive decline were modeled separately to determine if there was a significant change between baseline and year 10. We then tested whether gender and age at baseline predicted the trajectories of cognitive function and BMD. Two separate mixed-effect models corresponding to the MMSE and BMD trajectories were fitted with interaction terms for age group $(<75$ and $\geq 75$ years) * time (years) for women and men, separately using LSMEANS and Slice statements in SAS (SAS Institute, Inc., Cary, NC, USA).

Participants were then classified according to the outcome measurement: as having rapid bone loss (highest quartile) and no bone loss (remaining three quartiles). Baseline characteristics were compared between these two groups using $\chi^{2}$ for categorical variables and Student's $t$ test for continuous variables.

The longitudinal association between the rate of cognitive decline and bone loss was assessed using linear mixed-effect models to answer the question whether a significant change in the rate of cognitive function was associated with a significant change in the rate of bone loss. This model was adjusted for all potential confounding effects, including age, demographic measurements, education, comorbidities, lifestyle factors, and SF-36 components.

Approximately $8 \%$ of participants were missing at least one covariate used in the multivariable adjustment models (e.g., height, weight, SF-36 mental and physical scores). Values for the missing variables were imputed using multivariate imputation by the chained equations algorithm. ${ }^{(17)}$

Association between significant cognitive decline (baseline to year 5) and subsequent fracture risk (year 5 to year 15)

Participants were classified as having a significant cognitive decline if they lost three or more points on MMSE test between baseline and year 5 . First, we determined whether significant cognitive decline was associated with a decline in other parameters: anthropometric (height and weight), bone density, total SF36 components. The change in these parameters was calculated as percent change between baseline and year 5, and their association with significant cognitive decline was estimated using logistic regression.

Second, the association between significant cognitive decline and subsequent fracture risk was estimated using Cox proportional hazards models. Time to fracture was calculated from the year 5 visit to first incident fracture, or death, or end of the study, whichever came first. The fracture risk model was adjusted for baseline characteristics, as well as other factors that may impact fracture risk such as the decline in weight, ${ }^{(18)}$ height, ${ }^{(19)}$ bone density, and SF-36 components. The latter parameters were fitted both as continuous and categorical variables (worst quartiles vs. the remainder three quartiles). Only the categorical variables were associated with fracture risk and thus presented in Results. Interactions between declines in cognitive function, bone loss, and quality of life scores were assessed but none reached statistical significance.

Finally, we explored whether significant cognitive decline was associated with specific fracture types. Due to the small number of participants only two fracture groups were analyzed: (i) hip and vertebral; and (ii) NHNV. These models were also adjusted for all parameters included in the fracture risk model.

\section{Sensitivity analysis}

Of the total 581 fractures observed in women, 486 fractures were confirmed by $x$-ray report and included in the analysis. Of the remainder, participants with the first incident fracture not confirmed, a further seven participants experienced a second radiologically confirmed fracture. Thus, in total 88 (19 hip/vertebral and $69 \mathrm{NHNV}$ ) fractures were excluded. These fractures were excluded as events, and the relevant participants included in the nonfracture group. The association between significant cognitive impairment and fracture risk was ascertained by Cox proportional hazards model in a similar manner as described in the previous section.

All statistical analyses were performed using SAS version 9.4 (SAS Institute, Inc.). A $p$ value $<0.05$ was considered statistically significant.

\section{Results}

Rates of BMD and MMSE between baseline and year 10

There were 1741 women (mean \pm SD age $71 \pm 5$ years) and 620 men (mean $\pm S D$ age $71 \pm 5$ ) with at least two BMD and two MMSE measurements enrolled in the CaMos included in this study.

Women and men experienced a similar and significant decline in cognitive function during the first 10 years of follow-up ( $-4.5 \%$ [95\% Cl, $-5.2 \%$ to $-3.9 \%]$ and $-4.0 \%$ [95\% Cl, -5.1 to $-3.0 \%]$, for women and men, respectively; $p=0.42$ ). Older age at baseline was associated with a higher rate of cognitive decline in both genders (Figure S1).

Similar to the cognitive function trajectory, BMD also declined significantly for both genders, but was greater for women compared to men $(-3.4 \%[95 \% \mathrm{Cl},-3.9 \%$ to $-3.0 \%]$ and $-4.7 \%$ [95\% Cl, $-5.5 \%$ to $-4.0 \%]$, for women and men, respectively; $p=0.03$ ). Older age at baseline was also associated with a higher rate of bone loss in both genders (Figure S1).

Women and men in the highest quartile of bone loss $(-0.89 \%$ / year) were older, had a higher prevalence of hypertension and cardiovascular disease, lower femoral neck BMD, and lower physical and mental scores at baseline SF-36 compared to those who did not lose bone (Table 1, Table S1). In addition, women with the highest rate of bone loss also reported more chronic pulmonary disease, diabetes, and smoking, and were less likely to take hormone therapy at baseline (Table 1). 
Table 1. Baseline characteristics for women classified according to most rapid quartile of bone loss

\begin{tabular}{|c|c|c|c|c|}
\hline Characteristic & $\begin{array}{c}\text { Overall } \\
(n=1741)\end{array}$ & $\begin{array}{c}\text { Rapid bone loss }(>-0.89 \% / \\
\text { year) }(n=441)\end{array}$ & $\begin{array}{l}\text { No bone loss }(<-0.89 \% / \text { year }) \\
\qquad(n=1300)\end{array}$ & $p$ \\
\hline \multicolumn{5}{|l|}{ Baseline characteristic } \\
\hline Age (years), mean \pm SD & $71.0 \pm 4.7$ & $72.0 \pm 5.1$ & $70.6 \pm 4.5$ & $<0.0001$ \\
\hline University education, $n$ (\%) & $366(21.0)$ & $92(20.9)$ & $274(21.1)$ & 0.92 \\
\hline Weight $(\mathrm{kg})$, mean $\pm \mathrm{SD}$ & $67.7 \pm 12.5$ & $69.4 \pm 13.9$ & $67.1 \pm 11.9$ & 0.0006 \\
\hline Height $(\mathrm{cm})$, mean $\pm S D$ & $158.8 \pm 6.2$ & $158.6 \pm 6.4$ & $158.8 \pm 6.1$ & 0.46 \\
\hline Prior fracture, $n(\%)$ & $564(32.3)$ & $157(35.6)$ & $407(31.3)$ & 0.10 \\
\hline \multicolumn{5}{|l|}{ Comorbidities, $n(\%)$} \\
\hline Hypertension & $641(36.8)$ & $182(41.4)$ & $459(35.4)$ & 0.03 \\
\hline Chronic pulmonary disease & $150(8.6)$ & $53(12.7)$ & $97(8.1)$ & 0.005 \\
\hline Diabetes mellitus & $100(5.7)$ & $33(7.5)$ & $67(5.2)$ & 0.07 \\
\hline Cancer & $126(7.2)$ & $38(8.6)$ & $88(6.8)$ & 0.2 \\
\hline Cardiovascular & $166(9.5)$ & $62(14.1)$ & $104(8)$ & 0.0002 \\
\hline Neurological & $49(2.8)$ & $12(2.7)$ & $37(2.9)$ & 0.89 \\
\hline Vitamin D use, $n(\%)$ & $648(37.2)$ & $156(35.4)$ & $492(37.9)$ & 0.35 \\
\hline Hormone therapy, $n$ (\%) & $344(19.8)$ & $76(17.2)$ & $268(20.6)$ & 0.12 \\
\hline Bisphosphonate, $n(\%)$ & $65(3.7)$ & $17(3.9)$ & $48(3.7)$ & 0.88 \\
\hline Physical activity, $n$ (\%) & $1089(62.0)$ & $263(59.6)$ & $817(62.9)$ & 0.23 \\
\hline Current smoking, $n(\%)$ & $167(9.6)$ & $53(12.0)$ & $114(8.8)$ & 0.05 \\
\hline $\begin{array}{l}\text { Femoral neck BMD }\left(\mathrm{g} / \mathrm{cm}^{2}\right) \\
\text { mean } \pm S D\end{array}$ & $0.66 \pm 0.11$ & $0.68 \pm 0.11$ & $0.66 \pm 0.10$ & $<0.0001$ \\
\hline $\begin{array}{l}\text { Physical score (SF-36), } \\
\text { mean } \pm \text { SD }\end{array}$ & $46.1 \pm 9.6$ & $45.1 \pm 9.5$ & $46.5 \pm 9.6$ & 0.009 \\
\hline $\begin{array}{l}\text { Mental score (SF-36), } \\
\text { mean } \pm \text { SD }\end{array}$ & $54.2 \pm 8.2$ & $54.3 \pm 7.9$ & $53.6 \pm 8.9$ & 0.11 \\
\hline $\begin{array}{l}\text { Normal cognition (MMSE } \geq 24 \text { ), } \\
\quad n(\%)\end{array}$ & $1689(97.0)$ & $426(96.6)$ & $1263(97.2)$ & 0.36 \\
\hline
\end{tabular}

Note: Missing values (weight and height, $n=16$; hypertension, $n=5$; chronic pulmonary disease, $n=171$; diabetes, $n=1$; BMD, $n=61$; SF physical and mental score, $n=16$ ).

Abbreviations: BMD, bone mineral density; MMSE, Mini Mental State Examination; SF-36, Short Form 36 Health Survey.

\section{Association between longitudinal rates of cognitive decline and bone loss}

The longitudinal association between the rates of cognitive decline and bone loss was determined using linear mixed-effect models, with bone loss as the outcome. For women, bone loss was significantly associated with cognitive decline in both ageadjusted (7.01 [95\% Cl, 3.74 to 10.56] for each \% decline in MMSE) and multivariable-adjusted models $(6.49[95 \% \mathrm{Cl}, 3.17$ to 9.92$]$ for each \% decline in MMSE from baseline) (Table 2). Other significant predictors of bone loss were older age, presence of prior fracture, cancer, lack of regular physical activity, and lower physical scores on SF-36; whereas presence of diabetes at baseline was a predictor of increasing bone mass. For men, although there was a similar trend of more rapid bone loss being associated with more rapid cognitive decline, the magnitude of association was very small and not statistically significant $(0.58$ [95\% Cl, -3.91 to 5.28]; $p=0.80$ ). (Table S2).

Given that this study was unable to ascertain the direction of the association between cognitive decline and bone loss, we constructed an exploratory analysis that modeled the rate of cognitive decline as the outcome. Similar to the previous model, in women, the rate of cognitive decline was significantly associated with bone loss. However, given the more modest decline in BMD compared to MMSE (Figure S1), 1\% decline in BMD resulted in a lesser although significant decline in MMSE (multivariable adjusted model $2.8 \%$ decline in MMSE [95\% $\mathrm{Cl}, 1.1 \%$ to $4.7 \%$ ] for each \% decline in BMD) after adjustment for all baseline characteristics. In men, cognitive decline and bone loss had a similar magnitude of association as in women, but was not statistically significant $(2.0 \%$ [95\% Cl, $-1.1 \%$ to $5.1 \%$ ] for each \% decline in BMD). Other independent factors associated with significant cognitive decline were age, university education, height, and mental score in both genders (Table S3). In women, cognitive decline was also predicted by lower physical activity, and in men by smoking. These findings suggest both cognitive decline and bone loss are associated in a bidirectional manner for women. In men, the trend of association appears to be also bidirectional; however, the magnitude of association indicates that only cognitive decline analyzed as the outcome may be of clinical importance.

The association between significant cognitive decline and fracture risk

The association between significant cognitive decline, defined as a loss of at least three points on MMSE in the first 5 years, and subsequent fracture risk during the following 10 years of follow-up was estimated in the 2178 subjects (1608 women and 570 men), who had both BMD and MMSE measurements at baseline and year 5 . Of these, approximately $12 \%(n=272)$ experienced significant decline in MMSE score during the first 5 study years. Given the small number of men with significant cognitive decline $(n=86)$, this analysis was only performed in women. 
Table 2. Predictors of bone loss for women derived from the linear mixed effect model

\begin{tabular}{|c|c|c|}
\hline \multirow[b]{2}{*}{ Covariates } & \multicolumn{2}{|c|}{ Rates of bone loss from baseline $(95 \% \mathrm{Cl})$} \\
\hline & Age-adjusted & Multivariable adjusted $^{\mathrm{b}}$ \\
\hline Rate of cognitive decline from baseline $(-1 \%)$ & $7.10(3.74$ to 10.56$)$ & 6.49 (3.17 to 9.92$)$ \\
\hline Age $(+5$ years $)$ & $3.37(2.57$ to 4.17$)$ & $2.06(1.31$ to 2.82$)$ \\
\hline University education $^{a}$ & $-0.05(-1.81$ to 1.74$)$ & $-0.97(-2.56$ to 0.65$)$ \\
\hline Weight $(-5 \mathrm{~kg})$ & $2.40(2.12$ to 2.67$)$ & $2.21(1.91$ to 2.51$)$ \\
\hline Height $(-5 \mathrm{~cm})$ & $1.86(1.28$ to 2.45$)$ & $0.55(-0.01$ to 1.11$)$ \\
\hline Prior fracturea & $4.40(2.80$ to 6.02$)$ & $4.71(3.23$ to 6.21$)$ \\
\hline \multicolumn{3}{|l|}{ Comorbidities $^{\mathrm{a}}$} \\
\hline Hypertension & $-3.58(-4.96$ to -2.17$)$ & $-2.09(-3.40$ to -0.75$)$ \\
\hline Chronic pulmonary disease & $-0.06(-2.05$ to 1.98$)$ & $0.31(-1.55$ to 2.20$)$ \\
\hline Diabetes mellitus & $-5.84(-8.03$ to -3.60$)$ & $-3.51(-5.60$ to -1.36$)$ \\
\hline Cancer & $-2.94(-5.62$ to -0.19$)$ & $-2.14(-4.60$ to 0.39$)$ \\
\hline Cardiovascular & $-0.74(-3.18$ to 1.75$)$ & $-0.42(-2.67$ to 1.88$)$ \\
\hline Neurological & $4.08(0.17$ to 8.14$)$ & $3.73(0.16$ to 7.42$)$ \\
\hline Regular physical activity ${ }^{a}$ & $-0.90(-2.37$ to 0.59$)$ & $-1.40(-2.75$ to -0.02$)$ \\
\hline Current smoking $^{a}$ & 4.15 (1.62 to 6.75$)$ & $2.43(0.13$ to 4.79$)$ \\
\hline Physical score (SF-36) $(+10)$ & $1.10(0.40$ to 1.81$)$ & $0.13(-0.55$ to 0.82 \\
\hline Mental score (SF-36) $(+10)$ & $-0.48(-1.33$ to 0.38$)$ & $-0.40(-1.18$ to 0.38$)$ \\
\hline
\end{tabular}

Note: Bold values are significantly different at $p$ value $<0.05$.

Abbreviations: $\mathrm{Cl}$, confidence interval; SF-36, Short Form 36 Health Survey.

${ }^{a}$ Multivariable model included all variables presented in the table.

${ }^{\mathrm{b}}$ Yes versus no.

Table 3. Risk of any fracture (years 5-15) for women with cognitive decline compared to women without cognitive decline (years 0 and 5)

\begin{tabular}{|c|c|c|c|c|}
\hline Parameter & $\begin{array}{l}\text { Fracture } \\
(n=382)\end{array}$ & $\begin{array}{l}\text { No fracture } \\
(n=1226)\end{array}$ & $\begin{array}{c}\text { Age-adjusted HR } \\
(95 \% \mathrm{Cl})\end{array}$ & $\begin{array}{c}\text { Multivariable adjusted } \mathrm{HR}^{\mathrm{C}} \\
\qquad(95 \% \mathrm{Cl})\end{array}$ \\
\hline Cognitive decline, $n(\%)^{\mathrm{a}}$ & $50(13)$ & $136(11)$ & $1.68(1.16-2.43)$ & $1.61(1.11-2.34)$ \\
\hline Bone loss, $n(\%)^{\mathrm{b}}$ & $185(63)$ & $533(58)$ & $1.25(1.04-1.52)$ & $1.25(0.97-1.60)$ \\
\hline Age $(+5$ years $)$, mean $\pm S D$ & $72 \pm 5$ & $71 \pm 5$ & $1.21(1.07-1.37)$ & $1.12(0.98-1.27)$ \\
\hline University education, $n$ (\%) & $94(25)$ & $236(19)$ & $1.31(1.03-1.67)$ & $1.25(0.95-1.64)$ \\
\hline Prior fracture, $n(\%)$ & $200(52)$ & $451(37)$ & $1.55(1.25-1.91)$ & $1.49(1.16-1.90)$ \\
\hline \multicolumn{5}{|l|}{ Comorbidities, $n(\%)$} \\
\hline Hypertension & $214(56)$ & $676(55)$ & $1.05(0.85-1.30)$ & $1.08(0.84-1.38)$ \\
\hline Chronic pulmonary disease & $55(14)$ & $199(16)$ & $0.98(0.73-1.31)$ & $0.91(0.64-1.28)$ \\
\hline Diabetes mellitus & $38(10)$ & $149(12)$ & $0.96(0.68-1.34)$ & $0.88(0.58-1.33)$ \\
\hline Cancer & $72(19)$ & $263(22)$ & $0.90(0.69-1.17)$ & $0.90(0.67-1.21)$ \\
\hline Cardiovascular & $78(20)$ & $245(20)$ & $1.10(0.85-1.42)$ & $1.14(0.85-1.54)$ \\
\hline Neurological & $19(5)$ & $41(3)$ & $2.29(1.38-3.8)$ & $2.22(1.33-3.71)$ \\
\hline $\begin{array}{l}\text { Current smoking at } \\
\text { baseline, } n(\%)\end{array}$ & $35(9)$ & $121(10)$ & $1.02(0.70-1.48)$ & $0.96(0.61-1.51)$ \\
\hline Weight loss, $n(\%)^{\mathrm{b}}$ & $105(30)$ & $335(31)$ & $1.04(0.81-1.32)$ & $1.10(0.84-1.45)$ \\
\hline $\begin{array}{l}\text { Physical score (SF-36) } \\
\text { decline, } n(\%)^{\mathrm{b}}\end{array}$ & $126(34)$ & $347(29)$ & $1.29(1.03-1.62)$ & $1.19(0.91-1.56)$ \\
\hline $\begin{array}{l}\text { Mental score (SF-36) } \\
\text { decline, } n(\%)^{\mathrm{b}}\end{array}$ & $92(24)$ & $297(24)$ & $1.02(0.80-1.31)$ & $1.13(0.50-1.50)$ \\
\hline
\end{tabular}

Note: Bold values are significantly different at $p$ value $<0.05$.

Abbreviations: $\mathrm{Cl}$, confidence interval; HR, hazard ratio; MMSE, Mini Mental State Examination; SF-36, Short Form 36 Health Survey.

${ }^{a}$ Multivariable model included all variables in the table.

${ }^{\mathrm{b}}$ Decline $\geq 3$ MMSE points between baseline and year 5 .

${ }^{\mathrm{C}} \mathrm{Quartile}$ corresponding to the highest decline ( $\left.\leq-1 \% / \mathrm{year}\right)$.

Longitudinal association between significant cognitive decline with decline in functional and anthropometric measurements

Under the assumption that a significant cognitive decline is associated with decline in other parameters, we first assessed the change in available physical and anthropometric measurements between baseline and year 5 and evaluated their relationship with significant cognitive decline. Compared to women without cognitive function loss, women with significant cognitive decline 


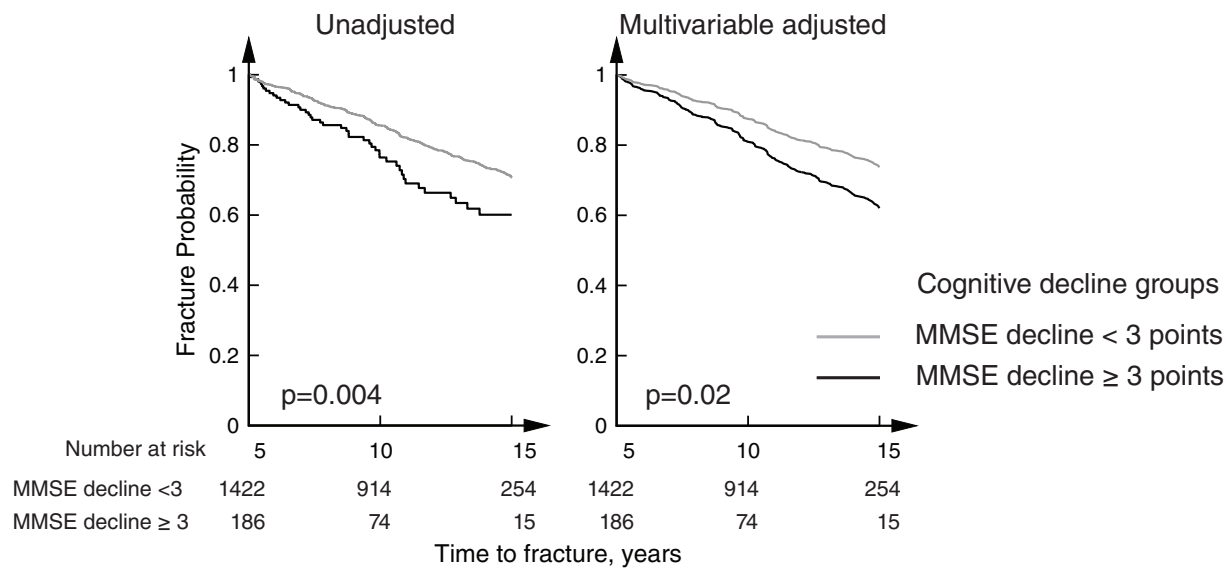

Fig. 2. Unadjusted and multivariable adjusted Kaplan-Meier fracture free probability curves for women with cognitive decline compared to women without cognitive decline (years 0 and 5). Abbreviation: MMSE, Mini Mental State Examination.

( $n=186$ ), also experienced a higher rate of bone loss (most rapid bone loss quartile, $34 \%$ vs. $24 \% ; p=0.008$ ), weight loss (greatest weight loss quartile: $36 \%$ vs. $27 \%$; $p=0.02$ ), decline in the physical component of SF-36 (highest quartile of decline $37 \%$ vs. $27 \%$; $p=0.006$ ), and mental component of SF-36 (most rapid decline: $34 \%$ vs. $23 \%$; $p=0.002$ ) during the first 5 study years.

\section{Association between cognitive decline and fracture risk}

After adjustment for age, significant cognitive decline was associated with $\sim 68 \%$ (age-adjusted $\mathrm{HR} 1.68 ; 95 \% \mathrm{Cl}, 1.16-2.43$ ) risk of osteoporotic fracture. Other risk factors for osteoporotic fracture in age-adjusted models were prior fracture, neurological conditions, lower level of education, and having a greater bone loss and change in the physical component of SF-36 between baseline and year 5 . After multivariable adjustment, the association between cognitive decline and fracture risk was only slightly attenuated (multivariable HR 1.61; 95\% Cl, 1.11-2.34) (Table 3, Figure 2). Other independent predictors for fracture risk in the multivariable model were prior fracture, neurological conditions, and greater bone loss.

A further analysis according to fracture type, demonstrated that individuals with significant cognitive decline had $\sim 96 \%$ higher risk of hip and vertebral fracture (multivariable HR 1.96; $95 \% \mathrm{Cl}, 1.05-3.67)$ and $\sim 57 \%$ higher risk of NHNV although this latter only reached marginally statistical significance after multivariable adjustment (HR 1.57; 95\% Cl, 0.99-2.48).

\section{Sensitivity analyses-exclusion of non-adjudicated fractures}

Similar findings, but with slightly higher magnitude, were observed in an analysis which included only fractures confirmed by $\mathrm{x}$-ray report ( $\sim 85 \%$ of the total fractures). In this analysis, cognitive decline was associated with $\sim 84 \%$ risk of osteoporotic fracture (adjusted HR 1.84; 95\% Cl, 1.24-2.73) after adjusting for all potential confounding effect, including bone loss and decline in SF-36 mental and physical performance components. The higher magnitude of association is most likely due to the exclusion of less severe fracture $(78 \%$ of not-confirmed fractures were NHNV fracture).

\section{Discussion}

This study reports a positive association between the rates of cognitive decline and bone loss in community dwelling women without dementia. Both women and men experienced significant declines in the rates of femoral neck BMD and cognitive decline over 10 years of follow-up. Despite these significant declines, the association between cognitive decline and bone loss was observed only for women. A decline in cognitive function by $1 \%$ over the 10 years follow-up was associated with a decline in bone loss by $\sim 6 \%$ during the same time interval, after adjustment for age, education, comorbidities, and lifestyle factors. By contrast, in men, there was no association between cognitive function and BMD beyond that expected by the normal aging process. A further analysis also showed that women who experienced a significant cognitive decline ( $\geq 3$ points on the MMSE) during the first 5 study years, had an $\sim 68 \%$ increased risk of fracture over the next 10 years, which was only mildly attenuated after adjustment for the concomitant loss in BMD, weight, and SF-36 components, as well as baseline variables associated with fracture risk BMD, falls, prior fracture, and comorbidities.

The novelty of this study resides in a comprehensive assessment of the relationship between trajectories of bone loss and cognitive decline over a 10-year interval. By contrast, the majority of the previous studies on this topic are mainly based on cross-sectional examination of the association between low BMD and low MMSE. ${ }^{(12,20)}$ Findings from these studies, although important, are limited in interpretation because a single low MMSE test is insufficient to predict those who will transition to cognitive impairment and further to dementia. Thus, findings from the current study provide stronger evidence for a potential causal association between osteoporosis and dementia.

This study contributes to the limited evidence of a positive association between low BMD and cognitive performance in elderly women. Two previous studies ${ }^{(11,12)}$ reported that either low BMD or bone loss predicted subsequent cognitive decline. In the "In CHIANTI" study, baseline cortical, but not trabecular tibial BMD estimated by peripheral quantitative computed tomography was associated with incident cognitive impairment and worsening of cognitive performance. ${ }^{(12)}$ Researchers from the Study of Osteoporotic Fractures reported that the highest 
rate of hip bone loss during the first 6 study years was associated with significant cognitive decline in the subsequent 4 years, and the association was not mediated by weight loss or the presence of apolipoprotein $E$ (ApoE) $\epsilon 4 .{ }^{(11)}$ Although, in the current study, the main outcome was bone loss, a similar positive and significant relationship was observed when the outcome was switched to cognitive decline, suggesting that the relationship between these two parameters could be bidirectional.

The pathological mechanisms behind this association are not known. One possible explanation could be that the association between bone loss and cognitive decline in women may be triggered by common predictors. Estrogen deficiency is independently associated with bone loss and cognitive decline and may play a role in mediating the association between these two parameters. ${ }^{(21)}$ Hormone therapy has a proven positive association with BMD and some evidence suggests that they may also improve cognition in postmenopausal women. ${ }^{(22,23)}$ It is not clear from the current study whether bone loss and cognitive decline are triggered by common factors or whether one causes the other.

This study is the first to our knowledge to report the association between the trajectories of BMD and cognitive performance in elderly men, albeit not a significant association. In this study, men experienced similar significant declines in the rates of bone loss and cognitive function during the 10 years of follow-up as women. However, in men, the association between the rates of bone loss and cognitive decline disappeared after age adjustment, indicating that the similar pattern of the two rates could simply be epiphenomena of the aging process. ${ }^{(11)}$ The reason for this gender difference is not clear; although, if estrogen is a common mediator, this may be a potential partial explanation. It is also possible that the findings from this study may simply be underpowered due the small sample size for men. Further larger studies are needed to confirm or not the association between bone loss and cognitive decline in men.

This study also demonstrated that women with significant cognitive decline have increased fracture risk, independent of the concomitant bone loss. Interestingly, a clinically significant decline in the cognitive function was associated with significant concomitant deterioration not only in bone mass but also weight, and physical and mental SF-36 scores. Notably, the contribution of cognitive decline on subsequent fracture risk was independent of these factors. Importantly, the risk was elevated not only for hip and vertebral but also for NHNV fractures. Although the association between cognitive decline and fracture risk has not been previously reported, the high prevalence of cognitive deficit and dementia among hip fracture patients is well known. ${ }^{(4)}$ It is thus possible that bone loss and cognitive decline are associated with a myriad of adverse conditions (e.g., weight loss, decline in quality of life), which leads to increased fracture risk. Furthermore, cognitive decline has been associated with increased risk of falling, which may also contribute to fracture risk. ${ }^{(24)}$ It is also not known, but worth investigating, whether these associations progress further and contribute to early dementia development.

Although the mechanisms of the association between bone loss and worsening of cognitive performance are not known, there are plausible explanations supported by preliminary data. Chronic systemic inflammation that increases with age has been separately associated with bone loss and cognitive decline. Proinflammatory cytokines, such as tumor necrosis factor alpha (TNF-alpha), interleukin 6 (IL-6), and IL-12 are associated with increased bone loss. ${ }^{(25)}$ Furthermore, bone resorption also contributes to the release of inflammatory cytokines leading to a vicious cycle of inflammation and bone resorption. On the other hand, there is compelling evidence that systemic inflammation may be associated with cognitive decline. In a cross-sectional study of over 800 women and men enrolled in the Sydney Memory and Ageing Study (MAS), markers of systemic inflammation such as raised levels of IL-12 and IL-6 were associated with reduced performance in processing speed, particularly for women. ${ }^{(26)}$ Additionally, in a recent study of patients undergoing total hip replacement for fragility fracture of the hip, we identified that bone expression of the Alzheimer disease/dementia-related genes APP and BACE1 correlated positively with bone resorption genes RANKL/TNFSF11 and TRAP/ $A C P 5$, and negatively with the radiographic and surrogate measure for bone loss at the femoral neck, lateral cortical thickness, ${ }^{(27)}$ supportive of common molecular pathways of the development of dementia and osteoporosis, an emerging area requiring further study.

This study has several strengths. The large number of repeated measurements allowed the estimation of the individual trajectories and the temporal association between bone loss and cognitive decline over 10 years. Moreover, the adjustment for a large number of factors related to both BMD and cognitive performance meant that the association observed between the deterioration of these parameters is likely to be true and beyond what is expected by the aging process. However, this study has some limitations. First, a large number of participants were excluded because they lacked two BMD and two MMSE measurements. The groups of participants excluded were older, sicker (more comorbidities, lower BMD and MMSE), and had worse lifestyle habits (higher prevalence of smokers and lower prevalence of regular physical activity). Nevertheless, the exclusion of this "sicker" group most likely underestimated our findings. Second, cognitive performance was only measured using the MMSE test, which does not provide accurate measurement of memory and executive function and is never used as a stand-alone test in dementia diagnosis. ${ }^{(28)}$ Further studies are needed to determine whether the decline in MMSE trajectories could be useful in monitoring the transition from mild cognitive impairment to dementia. Furthermore, in men, the analysis of the association between cognitive decline and bone loss was underpowered, and the association with fracture risk could not be performed in men due to the small sample size. Last, information on incident dementia was not documented in this study. Thus, we do not know whether or when people with significant cognitive decline developed dementia during the follow-up.

In summary, this study indicated that in women the rate of cognitive decline was significantly associated with bone loss, independent of age, education, comorbidities, and lifestyle factors. Notably, the relationship between bone loss and cognitive decline was bidirectional with no evidence of one preceding the other. Furthermore, a significant cognitive decline over 5 years was associated with an increased risk not only of hip and vertebral but also NHNV fractures over the subsequent 10 years. Importantly, fracture risk appeared to be only partly mediated by the concomitant increased rate of bone loss. Men, similar to women, experienced significant cognitive decline and bone loss during the study follow-up. However, the sample size was too small to accurately ascertain the relationship between the trajectories of bone mass and cognitive function.

These studies suggest that the relationship between bone loss, cognitive decline and fracture risk in women is driven by shared risk factors. Further mechanistic pathways are needed 
to understand the complex relationship between osteoporosis and dementia and the contributors of fracture risk in cognitively impaired people. This study failed to demonstrate a relationship between cognitive decline and bone loss in the relatively small cohort of men Thus, further studies, involving larger cohorts of men are needed to confirm or refute any association.

\section{Acknowledgments}

The Canadian Multicentre Osteoporosis Study was funded by the Canadian Institutes of Health Research (ClHR); Merck Frosst Canada Ltd.; Eli Lilly Canada Inc.; Novartis Pharmaceuticals Inc.; The Alliance: sanofi-aventis \& Procter and Gamble Pharmaceuticals Canada Inc.; Servier Canada Inc.; Amgen Canada Inc.; The Dairy Farmers of Canada; and The Arthritis Society. This work was supported by the National Health Medical Research Council Australia Projects 1070187, 1008219, and 1073430. Other funding bodies were an Osteoporosis Australia-Amgen grant; the Bupa Health Foundation (formerly MBF Foundation); the Mrs Gibson and Ernst Heine Family Foundation; and untied grants from Amgen, Merck Sharp \& Dohme, Sanofi-Aventis, Servier, and Novartis.

\section{Disclosures}

Jonathan D. Adachi has received research grants and/or personal fees from Amgen, Eli Lilly, Merck, Actavis, and AgNovos. Joop van den Bergh has received grants and/or personal fees from Amgen, MSD, and Eli Lilly. John A. Eisman has consulted for and/or received research funding from Amgen, deCode, Merck Sharp and Dohme, and Sanofi-Aventis. Piet Geusens was an advisory member for Amgen, and has received speaker fee and/or research grants from Amgen, Pfizer, MSD, UCB, Abbott, Lilly, BMS, Novartis, Roche and Will Pharma. David A. Hanley has consulted for and/or received speaker fee and/or research funding from Amgen, Merck, and Eli Lilly. Tuan V. Nguyen has received honoraria for consulting and symposia from Merck Sharp and Dohme, Roche, Servier, Sanofi-Aventis, and Novartis. Jerilynn C. Prior has consulted for and/or given educational talks for Merck Sharp and Dohme, Amgen, Actavis, Bayer, and SanofiAventis. Jacqueline R Center has consulted for and/or given educational talks for Amgen, Actavis and Bayer. Dana Bliuc, Thach Tran, Tineke van Geel, Claudie Berger, David Goltzman, Robert Josse, Lisa Langsetmo, Gerald J. Atkins, Lucian B. Solomon, Roberto Cappai, Catherine Stapledon, Christopher S. Kovacs, and Stephanie Kaiser have no competing interests to declare.

\section{Author Contributions}

All authors contributed to study conceptualization and design. Dana Bliuc, Thach Tran, Jonathan D. Adachi, Claudie Berger, David Goltzman, David A. Hanley, Robert Josse, Stephanie Kaiser, Christopher S. Kovacs, and Jacqueline R. Center contributed to data acquisition. Dana Bliuc, Thach Tran, and Jacqueline R. Center contributed to data analysis and manuscript drafting. All authors contributed to revising and approving the final version of the manuscript.

\section{Peer Review}

The peer review history for this article is available at https:// publons.com/publon/10.1002/jbmr.4402.

\section{Data Availability Statement}

The data that support the findings of this study are available from the corresponding author upon reasonable request.

\section{References}

1. Cooper C, Campion G, Melton LJ 3rd. Hip fractures in the elderly: a world-wide projection. Osteoporos Int. 1992;2(6):285-289.

2. Mayeux R, Stern Y. Epidemiology of Alzheimer disease. Cold Spring Harb Perspect Med. 2012;2(8):a006239.

3. Bliuc D, Nguyen ND, Milch VE, Nguyen TV, Eisman JA, Center JR. Mortality risk associated with low-trauma osteoporotic fracture and subsequent fracture in men and women. JAMA. 2009;301(5):513-521.

4. Vun JSH, Ahmadi M, Panteli M, Pountos I, Giannoudis PV. Dementia and fragility fractures: issues and solutions. Injury. 2017;48:S10-S16.

5. Haasum Y, Fastbom J, Fratiglioni L, Johnell K. Undertreatment of osteoporosis in persons with dementia? A population-based study. Osteoporos Int. 2012;23(3):1061-1068.

6. Friedman SM, Menzies IB, Bukata SV, Mendelson DA, Kates SL. Dementia and hip fractures: development of a pathogenic framework for understanding and studying risk. Geriatr Orthop Surg Rehabil. 2010;1(2):52-62.

7. Zhao Y, Shen L, Ji HF. Alzheimer's disease and risk of hip fracture: a meta-analysis study. ScientificWorldJournal. 2012;2012:872173.

8. Tsai $\mathrm{CH}$, Chuang $\mathrm{CS}$, Hung $\mathrm{CH}$, et al. Fracture as an independent risk factor of dementia: a nationwide population-based cohort study. Medicine. 2014;93(26):e188.

9. Bliuc D, Nguyen TV, Eisman JA, Center JR. The impact of nonhip nonvertebral fractures in elderly women and men. J Clin Endocrinol Metab. 2014;99(2):415-423.

10. Olofsson B, Persson M, Bellelli G, Morandi A, Gustafson Y, Stenvall M. Development of dementia in patients with femoral neck fracture who experience postoperative delirium - a three-year follow-up study. Int J Geriatr Psychiatry. 2018;33(4):623-632.

11. Lui LY, Stone K, Cauley JA, Hillier T, Yaffe K. Bone loss predicts subsequent cognitive decline in older women: the Study of Osteoporotic Fractures. J Am Geriatr Soc. 2003;51(1):38-43.

12. Laudisio A, Fontana DO, Rivera $C$, et al. Bone mineral density and cognitive decline in elderly women: results from the InCHIANTI study. Calcif Tissue Int. 2016;98(5):479-488.

13. Kreiger N, Tenenhouse A, Joseph L, et al. The Canadian Multicentre Osteoporosis Study (CaMos): background, rationale, methods. Can J Aging. 1999;18(3):376-387.

14. Hensel A, Angermeyer MC, Riedel-Heller SG. Measuring cognitive change in older adults: reliable change indices for the Mini-Mental State Examination. J Neurol Neurosurg Psychiatry. 2007;78(12): 1298-1303.

15. Stein J, Luppa M, Maier W, et al. Assessing cognitive changes in the elderly: reliable change indices for the Mini-Mental State Examination. Acta Psychiatr Scand. 2012;126(3):208-218.

16. Berger $C$, Goltzman $D$, Langsetmo $L$, et al. Peak bone mass from longitudinal data: implications for the prevalence, pathophysiology, and diagnosis of osteoporosis. J Bone Miner Res. 2010;25(9):1948-1957.

17. van Buuren S, Groothuis-Oudshoorn K. Mice: multivariate imputation by chained equations in R. J Stat Softw. 2011;45(3):67.

18. Ensrud KE, Ewing SK, Stone $\mathrm{KL}$, et al. Intentional and unintentional weight loss increase bone loss and hip fracture risk in older women. J Am Geriatr Soc. 2003;51(12):1740-1747.

19. Xu W, Perera S, Medich $D$, et al. Height loss, vertebral fractures, and the misclassification of osteoporosis. Bone. 2011;48(2):307-311. 
20. Kang HG, Park HY, Ryu HU, Suk S-H. Bone mineral loss and cognitive impairment: the PRESENT project. Medicine. 2018;97(41):e12755.

21. Hannan MT, Felson DT, Dawson-Hughes B, et al. Risk factors for longitudinal bone loss in elderly men and women: the Framingham Osteoporosis Study. J Bone Miner Res. 2000;15(4):710-720.

22. Wimalawansa SJ. Prevention and treatment of osteoporosis: efficacy of combination of hormone replacement therapy with other antiresorptive agents. J Clin Densitom. 2000;3(2):187-201.

23. Matthews K, Cauley J, Yaffe K, Zmuda JM. Estrogen replacement therapy and cognitive decline in older community women. J Am Geriatr Soc. 1999;47(5):518-523.

24. Shirooka H, Nishiguchi S, Fukutani N, Tashiro Y, Nozaki Y, Aoyama T. Subjective cognitive decline and fall risk in community-dwelling older adults with or without objective cognitive decline. Aging Clin Exp Res. 2018;30(5):457-462.
25. Mundy GR. Osteoporosis and inflammation. Nutr Rev. 2007;65(12 Pt 2):S147-S151.

26. Trollor JN, Smith E, Agars E, et al. The association between systemic inflammation and cognitive performance in the elderly: the Sydney Memory and Ageing Study. Age (Dordr). 2012;34(5): 1295-1308.

27. Stapledon CJM, Stamenkov R, Cappai R, et al. Relationships between the bone expression of Alzheimer's disease-related genes, bone remodelling genes and cortical bone structure in neck of femur fracture. Calcif Tissue Int. 2021;108(5):610-621.

28. Arevalo-Rodriguez I, Smailagic N, Roqué IFM, et al. Mini-Mental State Examination (MMSE) for the detection of Alzheimer's disease and other dementias in people with mild cognitive impairment (MCl). Cochrane Database Syst Rev. 2015;2015(3): CD010783. 